\title{
Coesite Formation at Ambient Pressure and Low Temperatures
}

\author{
J. R. Martínez, ${ }^{1,2}$ A. Vázquez-Durán, ${ }^{3}$ G. Martínez-Castañón, ${ }^{4}$ G. Ortega-Zarzosa, ${ }^{1}$ \\ S. A. Palomares-Sánchez, ${ }^{1}$ and Facundo Ruiz ${ }^{1}$ \\ ${ }^{1}$ Facultad de Ciencias, Universidad Autónoma de San Luis Potosí, 78000 San Luis Potosí, Mexico \\ ${ }^{2}$ Departamento de Físico-Matemáticas, Universidad Autónoma de San Luis Potosí, 78000 San Luis Potosí, Mexico \\ ${ }^{3}$ Centro de Investigación en Óptica, A.C., 37150 León, Gto., Mexico \\ ${ }^{4}$ Facultad de Estomatología, Universidad Autónoma de San Luis Potosí, 78000 San Luis Potosí, Mexico \\ Correspondence should be addressed to J. R. Martínez, flash@fciencias.uaslp.mx
}

Received 19 May 2008; Revised 16 July 2008; Accepted 21 July 2008

Recommended by Ming-Xing Zhang

Partial crystallization of silica xerogel in the form of coesite has been obtained at low-pressure conditions and temperatures of $\sim 565^{\circ} \mathrm{C}$, in samples containing chlorophyll aggregates dispersed in amorphous silica. Silica xerogel samples were prepared by the sol-gel method using an ethanol: $\mathrm{H}_{2} \mathrm{O}$ :TEOS molar ratio of 4:11.6:1 and loaded with extracts from frozen spinach leaves. The silica xerogel microstructure of the powders was studied as a function of annealing temperature. It was found that partial crystallization of the glass matrix in the form of coestite was obtained at lower pressure than those specified by the phase diagram. Chlorophyll aggregates were added to the starting solutions which, upon thermal treatments, form small colloidal particles in the glass matrix. The presence of coesite is corroborated by the Rietveld refinement method.

Copyright ( $\odot 2008$ J. R. Martínez et al. This is an open access article distributed under the Creative Commons Attribution License, which permits unrestricted use, distribution, and reproduction in any medium, provided the original work is properly cited.

\section{Introduction}

The crystallization of silica glasses has been investigated very soon after the discovery of glass. The rate and mechanism of crystallization vary with the chemical composition of the glass, temperature, and atmosphere. It has been observed that the presence of alkali metal, water, and oxygen accelerates the crystallization of glass. It is well known that the incorporation of metallic species in the silica xerogel matrix promotes the devitrification process at relatively low temperatures with the presence of partial crystallization in form of quartz or cristobalite [1-3]. The structural changes in the xerogel matrix are induced by the incorporation of particles and by the thermal treatment; however, the appearance of specific crystalline form of $\mathrm{SiO}_{2}$ is not clear.

Silicon dioxide, $\mathrm{SiO}_{2}$, may occur in several crystalline forms of which quartz is the most stable. However there are other polymorphs that may occur as minerals and/or as synthesized compounds. The most common polymorphs of silicon oxide are quartz, cristobalite, and tridymite. Dense and high-pressure forms of silica are the stishovite, olivine, and coesite. In natural form, the coesite is present in metha- morphism extreme in the underground of earth or in impact meteor sites.

Coesite, a high-pressure polymorph of $\mathrm{SiO}_{2}$, was first synthesized by Coes Jr [4], and was discovered subsequently as a mineral at Meteor Crater, Arizona [5].

Since that year, synthesis of coesite has been reported by some authors; coesite synthesized under high pressure, that is, $6.5 \mathrm{GPa}$ and $1375 \mathrm{~K}\left(1100^{\circ} \mathrm{C}\right)$ for the crystal was studied by Levien and Prewitt [6]. Coesite crystals were synthesized using a girdle solid-media, high-pressure apparatus where powdered crystals of quartz and silicic acid, $\mathrm{SiO}_{2} \mathrm{nH}_{2} \mathrm{O}$, were used as starting materials [7]. It was also synthesized in a single experiment at $700^{\circ} \mathrm{C}$ and $3.2 \mathrm{GPa}$ using an end-loaded piston-cylinder apparatus, using opal-A as the starting material [8], and in some other high-pressure experiments [8-14].

Coesite has eight unique $\mathrm{Si}-\mathrm{O}$ bonds and five unique $\mathrm{Si}-$ $\mathrm{O}-\mathrm{Si}$ groups in the unit cell [15], and it is an ideal material for studying the properties of the $\mathrm{SiO}$ bonds $[15,16]$. Coesite is a framework silicate in which each silicon atom is bonded to four oxygen atoms forming a silicate tetrahedron, and each oxygen atom is bonded to two silicon atoms forming a SiOSi 
disiloxy group. The structure of coesite is composed of $\mathrm{SiO}_{4}$ tetrahedrons that are linked into four-membered rings. The rings are then linked together into a chain-like structure, to form the so-called double crankshaft chain.

In this work, we report that the sol-gel-made amorphous $\mathrm{SiO}_{2}$ bulk samples containing extract of spinach are partially crystallized into coesite, obtained at much lower pressures than those specified by the phase diagram. For to achieve this, chlorophyll aggregates need to be added to the starting solutions which, upon thermal treatments form small colloidal particles in the glass matrix.

\section{Experimental Method}

The standard method to extract chlorophyll is by crude extraction from frozen spinach leaves by simple grinding and mixing with a suitable solvent. In order to obtain the organic compounds extracted from spinach leaves embedded in the xerogel matrix, a precursor material composed of TEOS, water, ethanol, and pigments extracted from spinach leaves was prepared [17]. The ethanol to TEOS and water to TEOS molar ratios were $4: 1$ and $11: 1$, respectively. This composition has proven to give good quality $\mathrm{SiO}_{2}$ coating. These quantities correspond to a high water/TEOS ratio, needed to enhance the hydrolysis [18] to assure a close amorphous structure for the as-prepared $\mathrm{SiO}_{2}$ powder, and to allow us to compare the results with some previous work [18-21]. The TEOS was dissolved in ethanol using magnetic stirring for 15 minutes. The suspension of pigments in water was added to the ethanol-TEOS solution to form the starting material.

The X-ray diffraction (XRD) patterns were obtained using a GBC-Difftech MMA diffractometer using nickel filtered $\mathrm{CuK} \alpha(\lambda=1.54 \AA)$ radiation. The infrared (IR) spectra were recorded with an FT-IR spectrometer Nicolet system model Avatar 360 using the diffuse reflectance (DR) mode, for which $0.05 \mathrm{~g}$ of powder sample was mixed with $0.3 \mathrm{~g}$ of $\mathrm{KBr}$. DTA measurements were carried out in a TA Instruments system, model Q600, at constant rate of $10^{\circ} \mathrm{C} / \mathrm{min}$ inside DTA analyzer in nitrogen atmosphere up to $600^{\circ} \mathrm{C}$.

X-ray data refinement was made using the program Maud in order to corroborate the presence of coesite and calculate the amorphous/crystalline fraction of the composites [22].

The program Maud was developed to analyze diffraction spectra and obtain crystal structures, quantity, and microstructure of phases along with the texture and residual stresses. It applied the RITA/RISTA method as developed by Wenk et al. [23] and Ferrari and Lutterotti [24].

The analysis was started assuming the structure of cubic $\mathrm{SiO}_{2}$ (cubic, spacegroup $\mathrm{P} 2{ }_{1} 3$ ) for the amorphous phase. For the crystalline phase of silica, the structure of coesite (monoclinic, spacegroup C 12/c1) was assumed.

The Rietveld analysis of amorphous phases is based on an improved microcrystallinity model that includes microstrains. Using the Rietveld method for glass modeling supposes that crystal structure may represent a mean model for a glass or a nanocrystalline material. The disorder

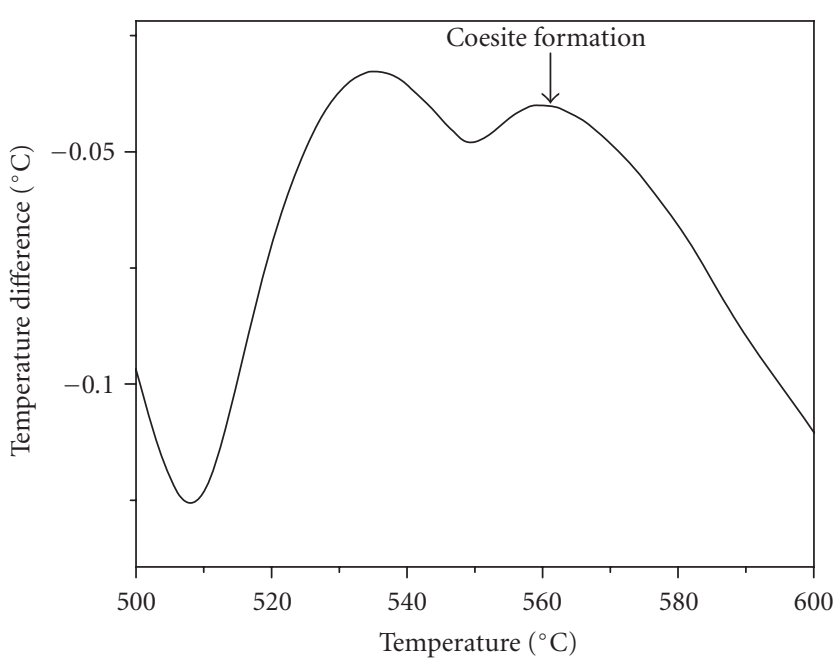

FIgURE 1: DTA curve of chlorophyll species embedded in a silica matrix heat-treated in nitrogen in the temperature range from $500^{\circ} \mathrm{C}$ to $600^{\circ} \mathrm{C}$.

is statistically introduced by microstrain effect, leading to strong line broadening on the diffraction pattern. This method has been tested in ceramic ware materials where it is very important to assess the product quality by checking the amorphous silica content [25].

\section{Results and Discussion}

In order to investigate the structural evolution of the compound, the as-prepared powder was heated at a constant rate of $10^{\circ} \mathrm{C} / \mathrm{min}$ inside a DTA analyzer in nitrogen atmosphere. Due to the fact that we only want to focus on the formation of the coesite phase, we show the DTA data in the range of $500^{\circ} \mathrm{C}$ to $600^{\circ} \mathrm{C}$; in such range, the analyzed sample gives endothermic peaks at $508^{\circ} \mathrm{C}$ and $549^{\circ} \mathrm{C}$, shown in Figure 1, and exothermic peaks at $535^{\circ} \mathrm{C}$ and $565^{\circ} \mathrm{C}$. After $400^{\circ} \mathrm{C}$ (not shown in the figure), a very broad endothermic process occurs due to decomposition of chlorophyll species, whereas it initiated the formation of phases of oxide and hydroxide magnesium transformation of gel to glass and the formation of crystalline phases of $\mathrm{SiO}_{2}$, as coesite.

According to the DTA data and X-ray diffraction pattern, not shown in the figures, at temperature above $600^{\circ} \mathrm{C}$ the coesite phase disappears and there begin to appear the cristobalite phase and the tridymite at temperatures above $800^{\circ} \mathrm{C}[26]$.

Figure 2 shows the X-ray diffractograms for the prepared samples. Embedded in amorphous silica xerogel, the chlorophyll species decomposed and interacted with the silica matrix promoting the formation of hydroxide magnesium species, quenching centers, or nonfluorescing aggregates due to denaturation of photosystem promoted by chlorophyll decomposition, and partial crystallization of the matrix, as discussed below.

Using both the results of DTA and X-ray diffraction, it can be seen that at temperatures lower than $600^{\circ} \mathrm{C}$, the composite powders are in amorphous form. The chlorophyll 


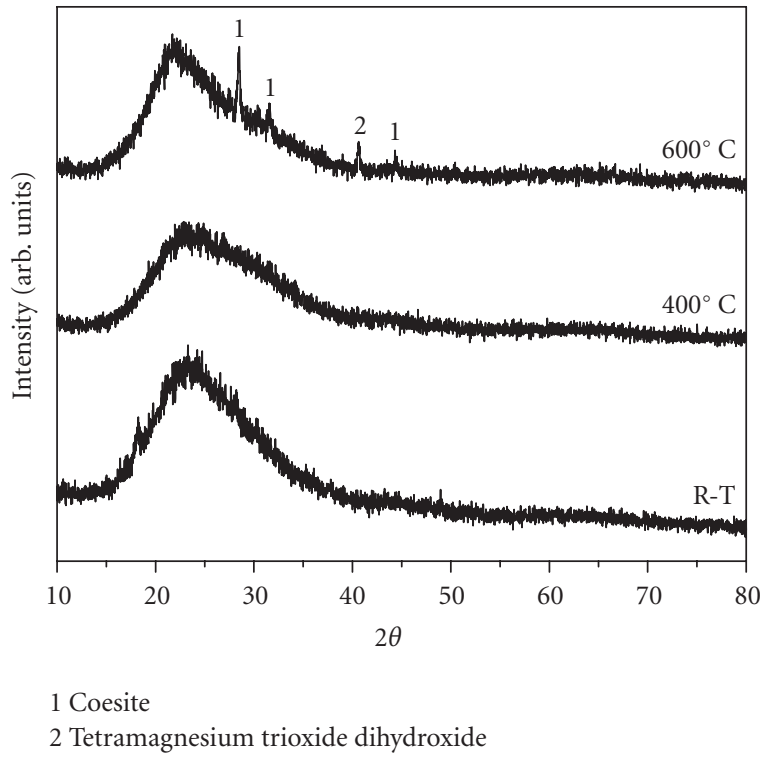

FIGURE 2: X-ray diffraction patterns of the chlorophyll-containing silica xerogel samples heat-treated at the indicated temperatures.

species decompose at temperatures of $\sim 222^{\circ} \mathrm{C}$, its decomposition conduces to the formation of magnesium hydroxide species and organic compounds that produce quenching centers and partial crystallization of $\mathrm{SiO}_{2}$ in the form of coesite, corresponding to the exothermic peaks at $565^{\circ} \mathrm{C}$. The exothermic peak at $535^{\circ} \mathrm{C}$ corresponds to the formation of tetramagnesium trioxide dihydroxide. The diffractogram clearly shows the presence of these phases at $600^{\circ} \mathrm{C}$.

In Figure 2, for the samples heat-treated below $600^{\circ} \mathrm{C}$, only the broad band corresponding to the $\mathrm{SiO}_{2}$ gel is present, which is extended to higher $2 \theta$-degrees due to the presence of chlorophyll species. In the sample heat-treated at $600^{\circ} \mathrm{C}$, besides the band assigned to silica, we observe narrow peaks, corresponding to coesite and tetramagnesium trioxide dihydroxide the last one centered at $\sim 40.5^{\circ}$.

The infrared absorption spectra in the range from $400 \mathrm{~cm}^{-1}$ to $4000 \mathrm{~cm}^{-1}$ are shown in Figure 3 . The bands at $457 \mathrm{~cm}^{-1}, 800 \mathrm{~cm}^{-1}$, and $1078 \mathrm{~cm}^{-1}$ are associated to absorption bands related to particular vibrational modes of the oxygen $(\mathrm{O})$ atom with respect to the silicon $(\mathrm{Si})$ atoms, which they bridge $[27,28]$. The principal band, located at about $1078 \mathrm{~cm}^{-1}$, has a strong absorption shoulder at its high-energy side that is more pronounced to conform to the temperature increased.

Several reports have been published concerning the highenergy shoulder of the stretching band, in the frequency range of 1150 to $1300 \mathrm{~cm}^{-1}$. For instance, in previous work, IR spectra have been reported in which these subbands can have an amplitude comparable or larger than the main stretching band at $1078 \mathrm{~cm}^{-1}[18,29]$. The enhanced intensity of these subbands has been interpretated as due to the formation of a chain- or ring-like structure. This band suffers significant modification with increasing annealing temperature. An explanation of this behavior will be proposed in the next parts of this section.

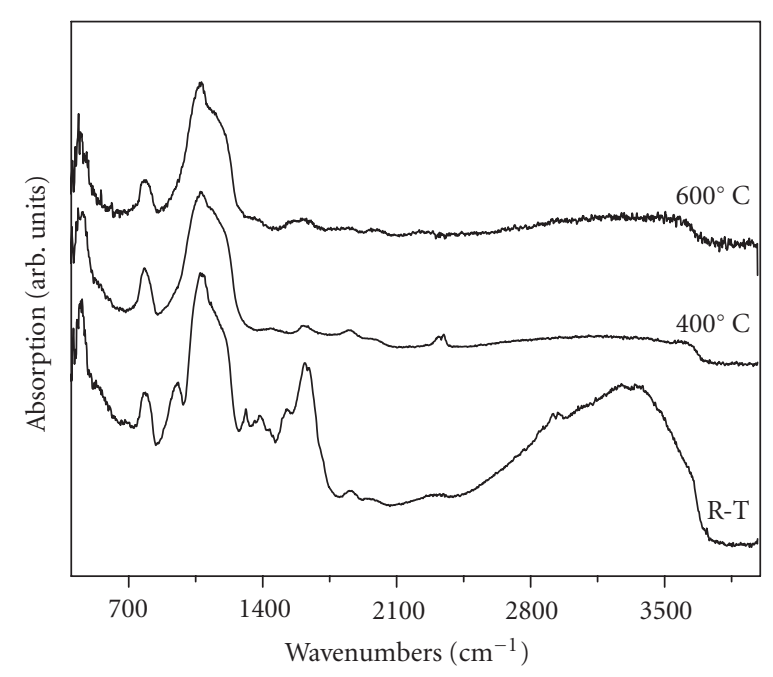

FIGURE 3: Infrared absorption spectra of the chlorophyll-containing silica xerogel samples.

A band centered at $950 \mathrm{~cm}^{-1}$, assigned to silanols ( $\mathrm{Si}$ $\mathrm{OH}$ ), is present at room temperature; for temperatures above $400^{\circ} \mathrm{C}$, the band is incorporated to the main stretching band conform the temperature is increased. We can also observe a band at $1600-1690 \mathrm{~cm}^{-1}$, assigned to the deformation of molecular water and to alkenyl $\mathrm{C}=\mathrm{C}$ stretch. This band is found in the spectra of the as-prepared sample, upon this temperature, the water is eliminated and only the alkenyl and $\mathrm{C}=\mathrm{C}-\mathrm{C}$ stretching and bending vibrations are present. It indicates that organic species, typical of green leaves, still exist in the structural conformation.

For samples heat-treated below $400^{\circ} \mathrm{C}$, the IR spectrum shows a strong absorption band at the range 1270$1560 \mathrm{~cm}^{-1}$. This band is associated with a combination of vibrations of the nitrate and $\mathrm{CH}$ species. The principal contributions are due to the $\mathrm{CH}$ group; from the figure we can observe that according to the increment of temperature, the band undergoes noticeable changes, indicating the evolution of chemical species. It is possible to see that, for samples heattreated at $600^{\circ} \mathrm{C}$, the band is partially incorporated to the main stretching band. In these temperatures, the composite shows an important phase transformation. Their presence at high temperature indicated, among the presence of organic compound in the composite, a preference linear structure of the matrix [30].

The band in the range of 2250 to $3000 \mathrm{~cm}^{-1}$ corresponds to the fundamental stretching vibrations of different hydroxyl groups [31]. The band is composed of a superposition of $\mathrm{SiO}-\mathrm{H}$ stretching vibrations. The weak band observed at $\sim 2800 \mathrm{~cm}^{-1}$ corresponds to $\mathrm{C}-\mathrm{H}$ stretching vibrations. This band is related to the band at the 1250 to $1550 \mathrm{~cm}^{-1}$. It is noticeable, according to the previous discussion, that for temperatures higher than $600^{\circ} \mathrm{C}$, these contributions are present.

The presence of these IR bands suggests that the structure includes polymerized species predominantly with oligomers. The formation of this kind of polysiloxanes is related to the 
presence of the IR bands at the range of 1250 to $1550 \mathrm{~cm}^{-1}$ and $2800-3000 \mathrm{~cm}^{-1}$; these bands tend to diminish by heat treatment indicating the evolution of the OR groups due to the chlorophyll decomposition. At the same time, the Si$\mathrm{O}-\mathrm{Si}$ chains in formation are terminated by $\mathrm{OH}$ species, as indicated by the presence of free surface silanols band $\left(3724 \mathrm{~cm}^{-1}\right) \mathrm{Si}-\mathrm{OH}$, as an evidence of the linear character. The permanence of these groups at elevated temperatures promotes, surprisingly, the partial devitrification with the formation of coesite phase in ambient pressure conditions; this has not been reported previously.

The IR absorption spectra of the sample heat-treated at $600^{\circ} \mathrm{C}$ show slight features associated with the coesite phase at the range from $440 \mathrm{~cm}^{-1}$ to $700 \mathrm{~cm}^{-1}$, in agreement with the X-ray results. Thus, the quantity of coesite present in the sample is very low.

Four-membered ring species are obtained in the early stages of the sol-gel process. In previous work, we have studied by means of quantum chemical calculations the vibrational frequency of oligosilsesquioxanes, which are composed of 4 -fold siloxane rings and cyclic trisiloxanes. In particular, we have obtained that a four-membered ring family is present in silica xerogels in the early stages of gelation process which remains during the conformation of the final structure. Three four-membered configurations are possible and the more stable configuration is the slightly deformed configuration [32]. That is close related with the double crankshaft chain formed by linking vierer rings that form the coesite structure.

As can be discussed, this four-membered slightly deformed species can be included with oligomers, that promotes partially the formation of double crankshaft chain characteristic of the coesite phase. At temperatures lower than $600^{\circ} \mathrm{C}$, the amorphous structure of the $\mathrm{SiO}_{2}$ matrix is closely related with the quartz-like amorphous. For the same formation parameters used in this work, we reported in previous work that for the silica xerogel matrix without incorporation of particles, we obtain close structures in which a transformation of quartz-like amorphous to lowcristobalite amorphous phase occurs at about $600^{\circ} \mathrm{C}[33]$.

It is known that the coesite phase can be obtained from quartz phase under high pressures. According to the present results, the sample promotes the formation of amorphous quartz-like for the matrix, obtaining oligomers species with four-membered sligthly deformed rings; under heat treatment the amorphous structure of the matrix evolutes to low-cristobalite amorphous phase but previously, the matrix promotes the partial devitrification in the form of coesite due to the presence of the organic compound in which the fourmembered rings are then linked together into a chain-like structure, resulting in the so-called double crankshaft chain characteristic of coesite.

In order to corroborate the presence of coesite, $\mathrm{X}$ ray data refinement was made using the program Maud. It has been shown that the method works also well to calculate the amorphous/crystalline fraction in composites with two crystalline phases, as in the case of the sample heat-treated at $600^{\circ} \mathrm{C}[21]$. In any case, very good agreement between experimental and calculated amorphous/crystalline

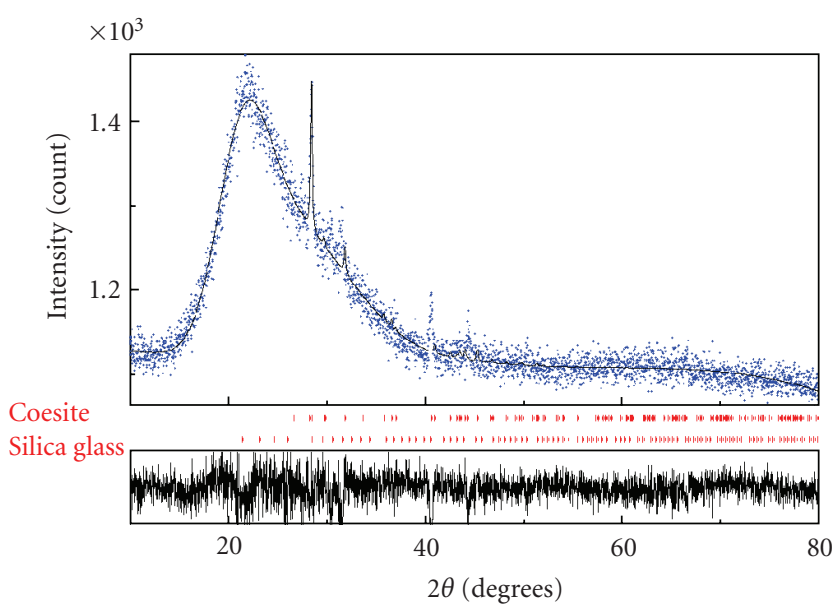

FIGURE 4: Experimental X-ray diffraction pattern of the sample heat-treated at $600^{\circ} \mathrm{C}$ together with the fitted spectrum. The difference is showed in the bottom of the figure.

fraction of composites was obtained [21, 22, 34, 35]. Figure 4 shows the X-ray diffraction pattern of the sample heattreated at $600^{\circ} \mathrm{C}$ along with the fitted spectrum, using the Maud program. The computed fraction of coesite phase is $1.25 \% \mathrm{wt}$, and the cell parameters are $a=7.137079 \AA, b=$ $12.409115 \AA$, and $\beta=120.50162^{\circ}$; these values are very close to those reported by Kroll and Milko [36].

In summary, for the sample heat-treated at $600^{\circ} \mathrm{C}$ we observed, among the magnesium oxide species, the presence of low-cristobalite amorphous phase and coesite phase. The presence of these two phases at this temperature is confirmed by the Rietveld refinement for amorphous $\mathrm{SiO}_{2}$. Using the above refinement process, the Bragg pattern and the peak position of the diffractograms correspond to the phases identified according to the spatial group $\mathrm{C} 12 / \mathrm{c} 1$ for the coesite and $\mathrm{P} 2{ }_{1} 3$ for the low-cristobalite.

The spatial group used for low-cristobalite is representative of the amorphous phase of the sample at this heat treated temperature. This fact is justified by the results shown in the X-ray diffractogram of Figure 2, for the amorphous band associated to the $\mathrm{SiO}_{2}$. The main feature of these patterns is a broadband located at the left part of the diffractogram. According to the treatment temperature, this band suffers a sligth shift to lower $2 \theta$-degrees. For the sample heat-treated at $400^{\circ} \mathrm{C}$, the position of the center is around $23.8^{\circ}$, and for the sample heat-treated at $600^{\circ} \mathrm{C}$ the position of the center is at $21.5^{\circ}$. It is important to note that cristobalite has its main diffraction peak at this position $\left(21^{\circ}\right)$.

In conclusion, we can assure the formation of the coesite phase, in this kind of samples prepared at ambient pressure and low temperatures. The existence of the phase is determined by using DTA results combined with X-ray diffractometry and Rietveld refinement method. This is a proven method to analyze and quantify the phases, both crystalline and amorphous, in a compound.

As it can be seen in Figure 2, there are some peaks produced by a crystalline structure that according to the refinement of its structure corresponds to the coesite. It is 
possible to quantify the phases, in this case, due to the large intensity of the peaks produced by any silicon oxide, even in so small quantities.

The diffraction pattern is composed by both amorphous and crystalline phases; due to the small quantity of coesite phase, some of the minor intensity peaks are screened by the amorphous phase. The refinement process is capable of separating the contribution of both phases. The results show very good fit between the refined and experimental patterns as it is shown in the bottom part of Figure 4. The principal peak does not match any other peaks of silicon oxide and it is in agreement with the structural parameters reported by Kroll and Milko [36].

The IR results show the formation of four-membered slightly deformed species included with oligomers, that promotes partially the formation of double crankshaft chain characteristic of the coesite phase.

\section{Conclusions}

This work shows that sol-gel-made amorphous $\mathrm{SiO}_{2}$ bulk samples can be crystallized into the coesite phase at temperatures of $565^{\circ} \mathrm{C}$ and at ambient pressure conditions. This is much lower than those specified by the phase diagram where the coesite is obtained at high pressures. The coesite phase had not been reported in this kind of xerogel matrix and mainly in low-pressure conditions. In order to achieve this phase, chlorophyll aggregates need to be added to the starting solutions. Embedded in the amorphous silica xerogel, the chlorophyll species decomposes and interacts with the silica matrix promoting the formation of hydroxide magnesium species, quenching centers or nonfluorescing aggregates due to denaturation of the photosystem promoted by chlorophyll decomposition, and partial crystallization of the matrix. At $600^{\circ} \mathrm{C}$, both the crystalline coesite phase and the amorphous phase coexist which was confirmed by the Rietveld refinement method.

\section{Acknowledgment}

This work was partially supported by Consejo Nacional de Ciencia y Tecnología, CONACYT-Mexico, under Grant no. 62013.

\section{References}

[1] G. A. Ozin, A. Kuperman, and A. Stein, "Advanced zeolite, materials science," Angewandte Chemie International Edition, vol. 28, no. 3, pp. 359-376, 1989.

[2] G. A. Ozin and S. Özkar, "Intrazeolite topotaxy," Advanced Materials, vol. 4, no. 1, pp. 11-22, 1992.

[3] N. Herron, Y. Wang, M. M. Eddy, et al., "Structure and optical properties of CdS superclusters in zeolite hosts," Journal of the American Chemical Society, vol. 111, no. 2, pp. 530-540, 1989.

[4] L. Coes Jr., "A new dense crystalline silica," Science, vol. 118, no. 3057, pp. 131-132, 1953.

[5] E. C. T. Chao, E. M. Shoemaker, and B. M. Madsen, "First natural occurrence of coesite," Science, vol. 132, no. 3421, pp. 220-222, 1960.
[6] L. Levien and C. T. Prewitt, "High-pressure crystal structure and compressibility of coesite," American Mineralogist, vol. 66, no. 3-4, pp. 324-333, 1981.

[7] S. Sasaki, H.-K. Chen, C. T. Prewitt, and Y. Nakajima, "Reexamination of " $P 2_{1} / a$ " coesite," Zeitschrift für Kristallographie, vol. 164, pp. 67-77, 1983.

[8] J. R. Michalski, M. D. Kraft, T. Diedrich, T. G. Sharp, and P. R. Christensen, "Thermal emission spectroscopy of the silica polymorphs and considerations for remote sensing of Mars," Geophysical Research Letters, vol. 30, no. 19, pp. PLA2-1PLA2-4, 2003.

[9] J. L. Mosenfelder, "Pressure dependence of hydroxyl solubility in coesite," Physics and Chemistry of Minerals, vol. 27, no. 9, pp. 610-617, 2000.

[10] W. L. Gong, L. M. Wang, R. C. Ewing, and H. S. Xie, "Interface-mediated amorphization of coesite by $200 \mathrm{keV}$ electron irradiation," Journal of Applied Physics, vol. 81, no. 6, pp. 2570-2574, 1997.

[11] F. S. El'kin, V. V. Brazhkin, L. G. Khvostantsev, O. B. Tsiok, and A. G. Lyapin, "In situ study of the mechanism of formation of pressure-densified $\mathrm{SiO}_{2}$ glasses," JETP Letters, vol. 75, no. 7, pp. 342-347, 2002.

[12] J. P. Petitet and V. L. Solozhenko, "Phase transformations in the $\mathrm{TiO}_{2}-\mathrm{SiO}_{2}$ system at high pressures and temperatures," High Pressure Research, vol. 23, no. 4, pp. 465-470, 2003.

[13] K. Ye, J.-B. Liou, B. Cong, and Sh. Maruyama, "Overpressures induced by coesite-quartz transition in zircon," American Mineralogist, vol. 86, no. 10, pp. 1151-1155, 2001.

[14] C. Lathe, M. Koch-Müller, R. Wirth, et al., "The influence of $\mathrm{OH}$ in coesite on the kinetics of the coesite-quartz phase transition," American Mineralogist, vol. 90, no. 1, pp. 36-43, 2005.

[15] J. W. Downs, "Electron density and electrostatic potential of coesite," The Journal of Physical Chemistry, vol. 99, no. 18, pp. 6849-6856, 1995.

[16] K. L. Geisinger, M. A. Spackman, and G. V. Gibbs, "Exploration of structure, electron density distribution, and bonding in coesite with Fourier and pseudoatom refinement methods using single-crystal X-ray diffraction data," The Journal of Physical Chemistry, vol. 91, no. 12, pp. 3237-3244, 1987.

[17] A. Vázquez-Durán, C. Araujo-Andrade, G. MartínezCastañón, G. Ortega-Zarzosa, F. Ruiz, and J. R. Martínez, "Spectral characterization of chlorophyll fluorescence in extract of barley leaves embedded in silica xerogel matrix," Journal of Sol-Gel Science and Technology, vol. 39, no. 3, pp. 223-227, 2006.

[18] J. R. Martínez, F. Ruiz, Y. V. Vorobiev, F. Pérez-Robles, and J. González-Hernández, "Infrared spectroscopy analysis of the local atomic structure in silica prepared by sol-gel," The Journal of Chemical Physics, vol. 109, no. 17, pp. 7511-7514, 1998.

[19] J. R. Martínez, G. Ortega-Zarzosa, O. Domínguez-Espinós, and F. Ruiz, "Low temperature devitrification of $\mathrm{Ag} / \mathrm{SiO}_{2}$ and $\mathrm{Ag}(\mathrm{CuO}) / \mathrm{SiO}_{2}$ composites," Journal of Non-Crystalline Solids, vol. 282, no. 2-3, pp. 317-320, 2001.

[20] G. Ortega-Zarzosa, J. R. Martínez, A. Robledo-Cabrera, G. A. Martínez-Castañón, M. G. Sánchez-Loredo, and F. Ruiz, "Annealing behavior of silica gel powders modified with silver crystalline aggregates," Journal of Sol-Gel Science and Technology, vol. 27, no. 3, pp. 255-262, 2003.

[21] S. A. Palomares Sánchez, S. Ponce-Castañeda, J. R. Martínez, F. Ruiz, Y. Chumakov, and O. Domínguez, "Quantitative analysis 
of iron oxide particles embedded in an amorphous xerogel matrix," Journal of Non-Crystalline Solids, vol. 325, no. 1-3, pp. 251-257, 2003.

[22] A. Le Bail, "Modelling the silica glass structure by the Rietveld method," Journal of Non-Crystalline Solids, vol. 183, no. 1-2, pp. 32-42, 1995.

[23] H.-R. Wenk, S. Matthies, and L. Lutterotti, "Texture analysis from diffraction spectra," Materials Science Forum, vol. 157162, pp. 473-480, 1994.

[24] M. Ferrari and L. Lutterotti, "Method for the simultaneous determination of anisotropic residual stresses and texture by X-ray diffraction," Journal of Applied Physics, vol. 76, no. 11, pp. 7246-7255, 1994.

[25] L. Lutterotti, R. Ceccato, R. Dal Maschio, and E. Pagani, "Quantitative analysis of silicate glass in ceramic materials by the Rietveld method," Materials Science Forum, vol. 278-281, pp. 87-92, 1998.

[26] J. R. Martínez, G. A. Martínez-Castañón, G. Ortega-Zarzosa, J. A. de la Cruz-Mendoza, S. A. Palomares-Sánchez, and F. Ruiz, "Structural effects of heat-treated silica xerogel induced by incorporation of chlorophyll species," Research Letters in Materials Science, vol. 2007, Article ID 23018, 5 pages, 2007.

[27] P. N. Sen and M. F. Thorpe, "Phonons in $A X_{2}$ glasses: from molecular to band-like modes," Physical Review B, vol. 15, no. 8, pp. 4030-4038, 1977.

[28] F. L. Galeener, "Band limits and the vibrational spectra of tetrahedral glasses," Physical Review B, vol. 19, no. 8, pp. 42924297, 1979.

[29] J. R. Martínez, F. Ruiz, J. A. de la Cruz-Mendoza, et al., "Structural evolution of silica-gel in the late stages of the gelation process," Revista Mexicana de Física, vol. 44, no. 6, pp. 575-579, 1998.

[30] G. Ortega-Zarzosa, C. Araujo-Andrade, M. E. Compeán-Jasso, J. R. Martínez, and F. Ruiz, "Cobalt oxide/silica xerogels powders: X-ray diffraction, infrared and visible absorption studies," Journal of Sol-Gel Science and Technology, vol. 24, no. 1, pp. 23-29, 2002.

[31] G. Orcel, J. Phalippou, and L. L. Hench, "Structural changes of silica xerogels during low temperature dehydration," Journal of Non-Crystalline Solids, vol. 88, no. 1, pp. 114-130, 1986.

[32] E. Monsivais-Gámez, F. Ruiz, and J. R. Martínez, "Fourmembered rings family in the Si-O extended rocking IR band from quantum chemistry calculations," Journal of SolGel Science and Technology, vol. 43, no. 1, pp. 65-72, 2007.

[33] J. R. Martínez, S. Palomares-Sánchez, G. Ortega-Zarzosa, F. Ruiz, and Y. Chumakov, "Rietveld refinement of amorphous $\mathrm{SiO}_{2}$ prepared via sol-gel method," Materials Letters, vol. 60, no. 29-30, pp. 3526-3529, 2006.

[34] S. A. Palomares Sánchez, S. Ponce-Castañeda, J. R. Martínez, and F. Ruiz, "Determination of phases of $\alpha-\mathrm{Fe}_{2} \mathrm{O}_{3}: \mathrm{SiO}_{2}$ compound by the Rietveld refinement," Revista Mexicana de Física, vol. 48, no. 5, pp. 438-442, 2002.

[35] S. Ponce-Castañeda, J. R. Martínez, S. A. Palomares Sánchez, F. Ruiz, and J. A. Matutes-Aquino, "Formation of nickel-zinc ferrite embedded in a silica xerogel matrix," Journal of Sol-Gel Science and Technology, vol. 25, no. 1, pp. 37-41, 2002.

[36] P. Kroll and M. Milko, "Theoretical investigation of the solid state reaction of silicon nitride and silicon dioxide forming silicon oxynitride $\left(\mathrm{Si}_{2} \mathrm{~N}_{2} \mathrm{O}\right)$ under pressure," Zeitschrift für Anorganische und Allgemeine Chemie, vol. 629, no. 10, pp. 1737-1750, 2003. 

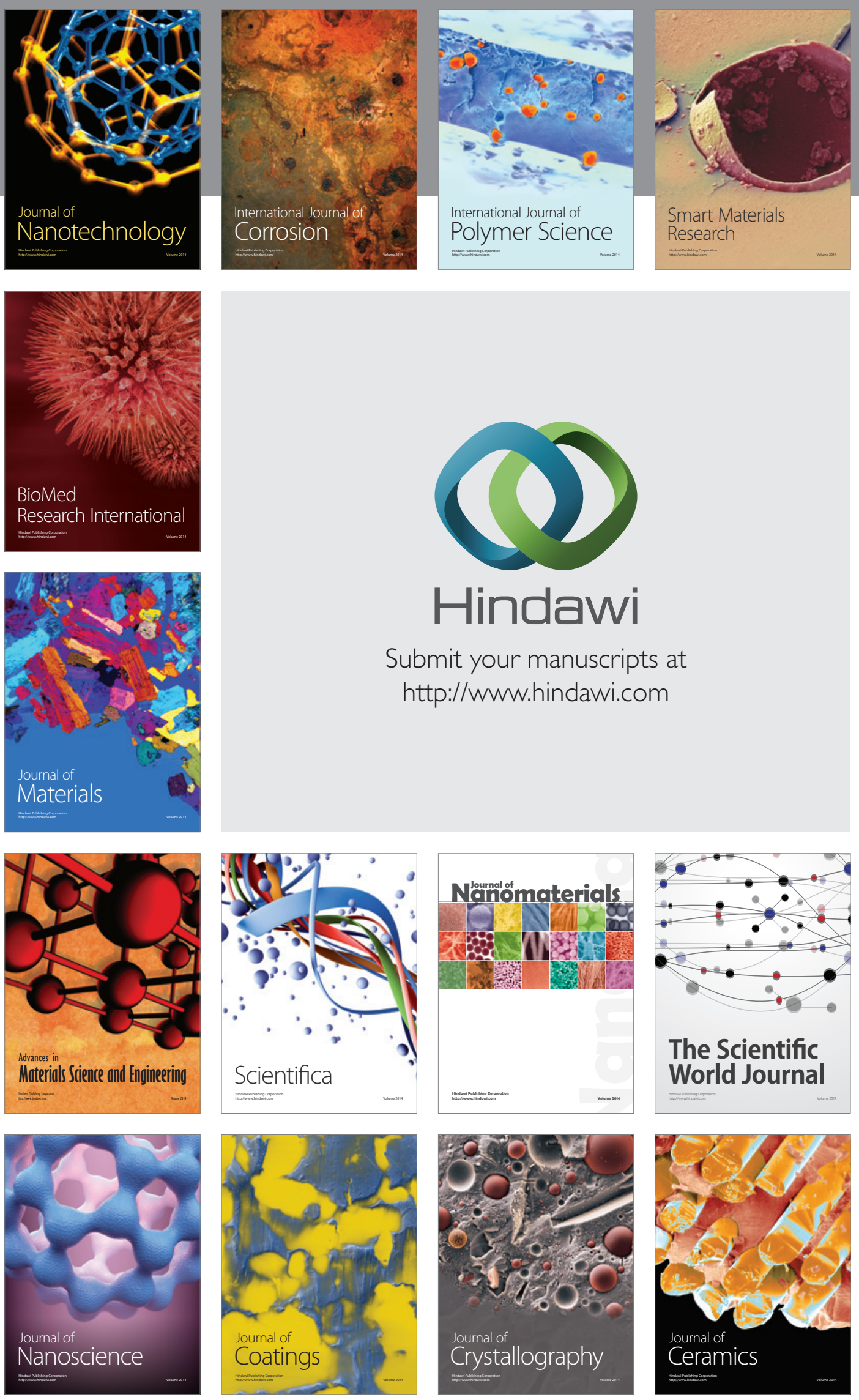

The Scientific World Journal

Submit your manuscripts at

http://www.hindawi.com

\section{World Journal}

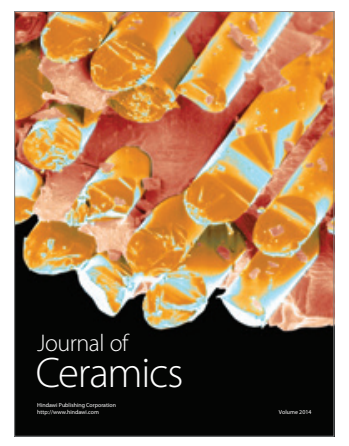

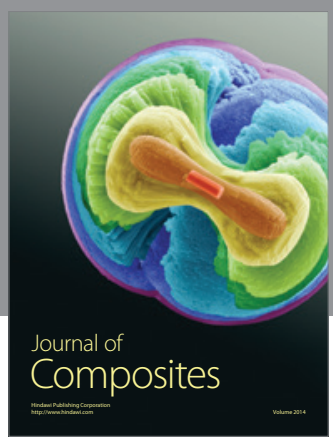
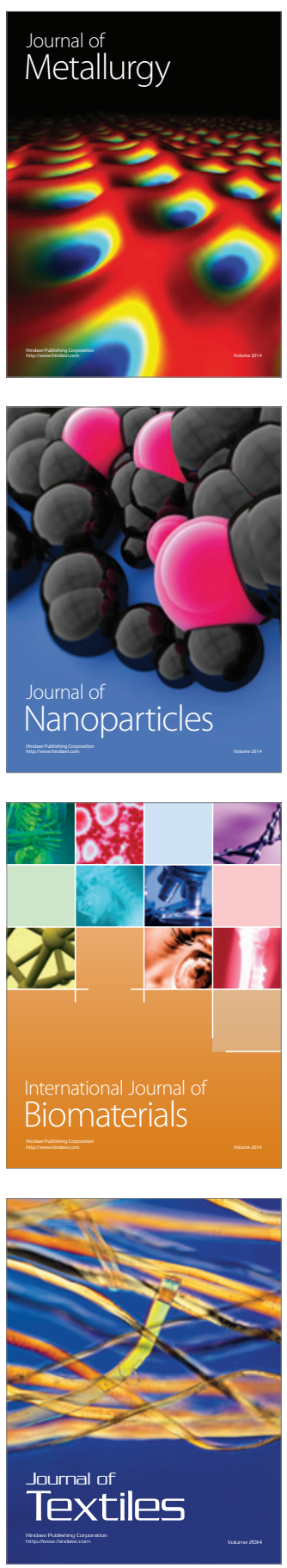